\title{
Advancement of a smart fibrous capillary irrigation management system with an Internet of Things integration
}

\author{
Muhammad Khairie Idham Abd Rahman, Mohamad Shukri Zainal Abidin, Mohd Saiful Azimi \\ Mahmud, Salinda Buyamin, Mohamad Hafis Izran Ishak, Abioye Abiodun Emmanuel \\ School of Electrical Engineering, Faculty of Engineering, Universiti Teknologi Malaysia (UTM), 81310 Skudai, Johor \\ Bahru, Malaysia
}

\begin{tabular}{l} 
Article Info \\
\hline Article history: \\
Received Mar 29, 2019 \\
Revised May 25, 2019 \\
Accepted Jun 18, 2019 \\
\hline
\end{tabular}

\section{Keywords:}

Evapotranspiration Fibrous capillary irrigation Internet of Things Monitoring system Soil moisture content

\section{Corresponding Author:}

Mohamad Shukri Zainal Abidin

School of Electrical Engineering, Faculty of Engineering, Universiti Teknologi Malaysia (UTM), 81310 Skudai, Johor Bahru, Malaysia.

Email: shukri@utm.my

\begin{abstract}
This paper presents the development work for integrating an Internet of Things (IoT) with a fibrous capillary irrigation system based on the climatic demand estimated by the weather condition. The monitoring and control using an IoT system is critical for such application that is targeted for precision irrigation. The fibrous capillary irrigation system is managed by manipulating a water supply depth using the potential evapotranspiration (ETo). A soil mositure sensor was used to monitor the progress of the root water uptake and input the fuzzy logic system, to determine the water requirements for the crop medium. Experiment was conducted by using a Choy sum plant as the test crop grown in a greenhouse. The monitoring of the demand and management of the watering system was successful. The ETo data was able to approximate the crop water requirement in near real time.
\end{abstract}

Copyright $\odot 2019$ Institute of Advanced Engineering and Science. All rights reserved.

\section{INTRODUCTION}

By the year 2050, the world will need to produce $70 \%$ more food, in order to feed the growing population on the earth, according to the Food and Agriculture Organisation of the United Nations (FAO) [1]. In order to meet this demand, farmers and the agricultural companies are nowadays focusing on the Internet of Things (IoT) for analytical and monitoring tools, so as to enhance crop management for a greater production of produce[2-4]. The IoT is capable of providing information about crop yields, rainfall, pest infestation and soil nutrition, which is invaluable for this extra produce production and it offers precise data, which can then be used to improve techniques over time [2,5-7]. In a precision agriculture irrigation system, the supply of water is required to be at the right volume, at the right time and at the right location $[8,9]$. However, in order to measure the demand of plant water in real time, it becomes impossible without a parameter or a sensor to measure it. Thus, a potential evapotranspiration (ETo) parameter has now been introduced for a reference plant water uptake and it enables an estimation of the amount of water for an optimum growth [10].

This parameter also displays a great potential to save water, while at the same time, it improves the productivity of agricultural based products [11,12]. ETo is a term that is used to describe the amount of water that is consumed by plants over a period of time, where a natural water loss occurs from the processes of evaporation and transpiration [13, 14]. Evaporation occurs when water changes into a vapour on the soil surface. Transpiration refers to the water loss that occurs through the leaves of the plant. By knowing the actual ETo level, the volume of water loss can be determined and the exact amount can then be applied, in order to replace what the plant field is losing $[15,16]$. 
The evapotranspiration (ETo) level increases, whenever the atmospheric demand is increased, because it strongly pulls water through the plant [17]. There are two factors that can be used to estimate irrigation. These factors are the local weather conditions and the cropping system, such as the type of crop, the planting date and the crop's development. The local weather conditions are important, because the ETo is driven by the weather factors. The ETo losses can be predicted accurately, by the measurements of four local weather variables, which are temperature, humidity, solar radiation and wind speed $[18,19]$.

It has been well established that by using an estimated ETo as a guide for irrigation, can avoid the misapplications of water [20, 21]. However, researchers are now trying to control the water supply depth by fibrous capillary irrigation, based on the ETo parameters and the soil water balance [22]. The fibrous capillary irrigation system is known as a sub-irrigation system that was developed as an alternative watering method for precision agriculture. This irrigation technique can offer a high amount of water saving by delivering the water directly into the root zone [23]. However, the watering by capillary irrigation makes the medium continuously wet. This is while certain types of crop need a wet-dry cycle irrigation system for their growth $[24,25]$.

With a proper management of the water supply depth, the fibrous capillary irrigation can be controlled at the correct volume and it can be delivered at the right time. However, it is still difficult to determine the exact amount of plant water uptake in the field, because of the dynamic plant water uptake, as well as with the challenge of providing farmers with information in real-time, about the status of their crops, in order to enhance their farming efficiency. Hence, the objective of this study was to design a smart irrigation system based on real-time data, by using the IoT, to support the management and the decision-making for an irrigation volume. The Penman-Monteith equation for estimating the evapotranspiration was used to evaluate the fibrous capillary irrigation system on the crop.

\section{RESEARCH METHOD}

\subsection{System overview}

Figure 1 shows the block diagram of the IoT system for the management of the fibrous capillary irrigation system. This system consist of two parts, a weather station and an irrigation controller. The weather station used is Davis Vantage Pro 2 sensor, which was built with solar radiation estimator, a UV sensor, a rainfall collector and an anemometer sensor. The irrigation controller had several components that were attached to an Arduino Mega board, which were, namely, a soil moisture sensor, a Wi-Fi shield, an ultrasonic distance sensor and a water pump. The estimated potential evapotranspiration and the soil moisture data were used as an input, in order to determine the water supply depth levels.

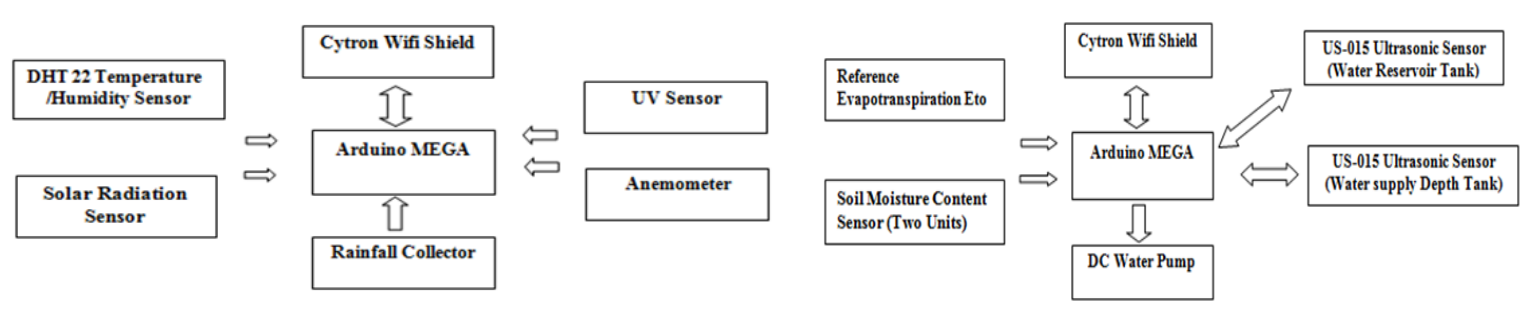

(a)

(b)

Figure 1. Block diagram of the IoT based weather station system, (a) and block diagram of the IoT based, (b) Irrigation controller system

\subsection{Architecture}

The IoT based fibrous capillary irrigation system consist of a weather station and a controller system for the management of the water supply depth, as shown in Figure 2. Figure 3 shows the experimental setup for the fibrous capillary irrigation system. 


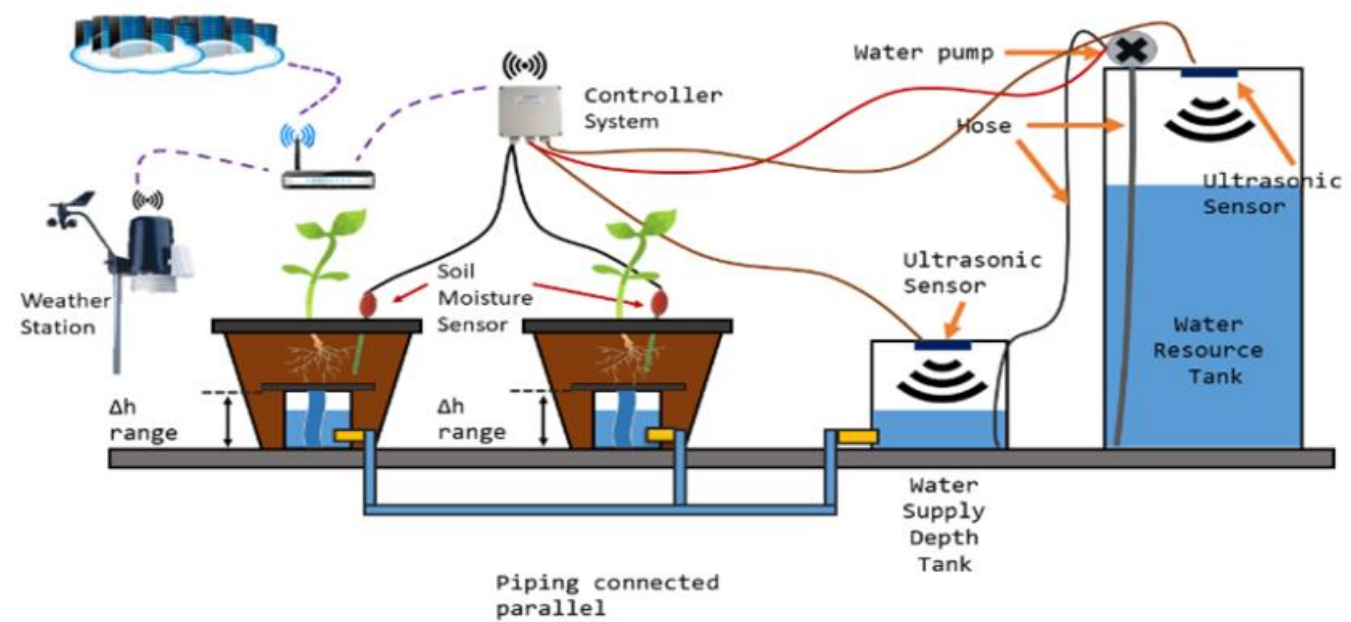

Figure 2. Fibrous capillary irrigation system with the IoT monitoring system layout

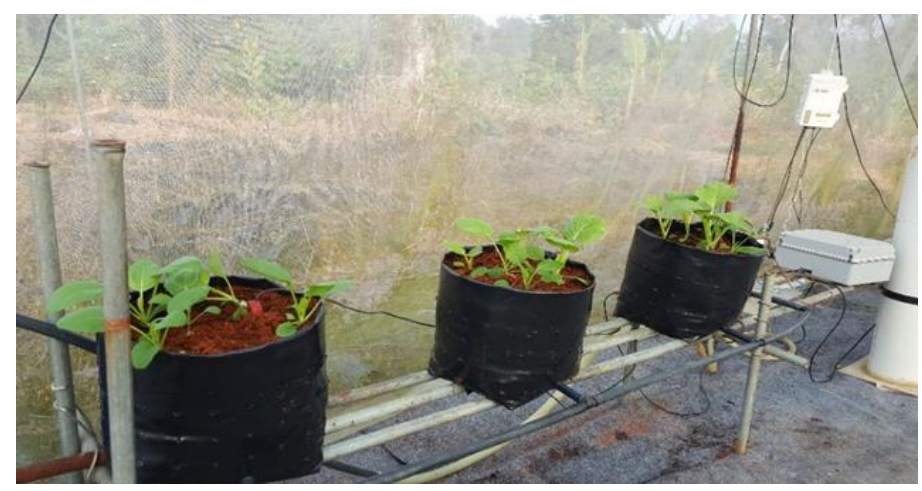

Figure 3. Experimental setup for the fibrous capillary irrigation with the IoT monitoring system

\subsection{Irrigation process of the fibrous capillary irrigation}

Figure 4 provides an overview of the fibrous capillary irrigation process. In order to set up everything for the required water supply depth $(\Delta \mathrm{h})$, the controller had to determine how much water was required to be supplied. This supply was based on the data that was obtained from the weather station and from the soil water content. The data was then analysed, in order to estimate the crop water demand value. The data was then stored into a cloud server and to the microcontroller at every 10 minutes. At one-hour sampling time, the data was averaged to be inserted into the fuzzy expert system as the input value.

The actual evapotranspiration and the available water contents were determined by the fuzzy expert system, in order to determine the $\Delta \mathrm{h}$. Once the $\Delta \mathrm{h}$ had been identified by the controller, it then regulated the $\Delta \mathrm{h}$ in the water supply depth tank, by manipulating the water pump. The excess water in the supply depth tank in the regulation process was absorbed by the plant during the root water uptakes. The data for a certain growth period was used, so as to analyse for the total water consumption. 


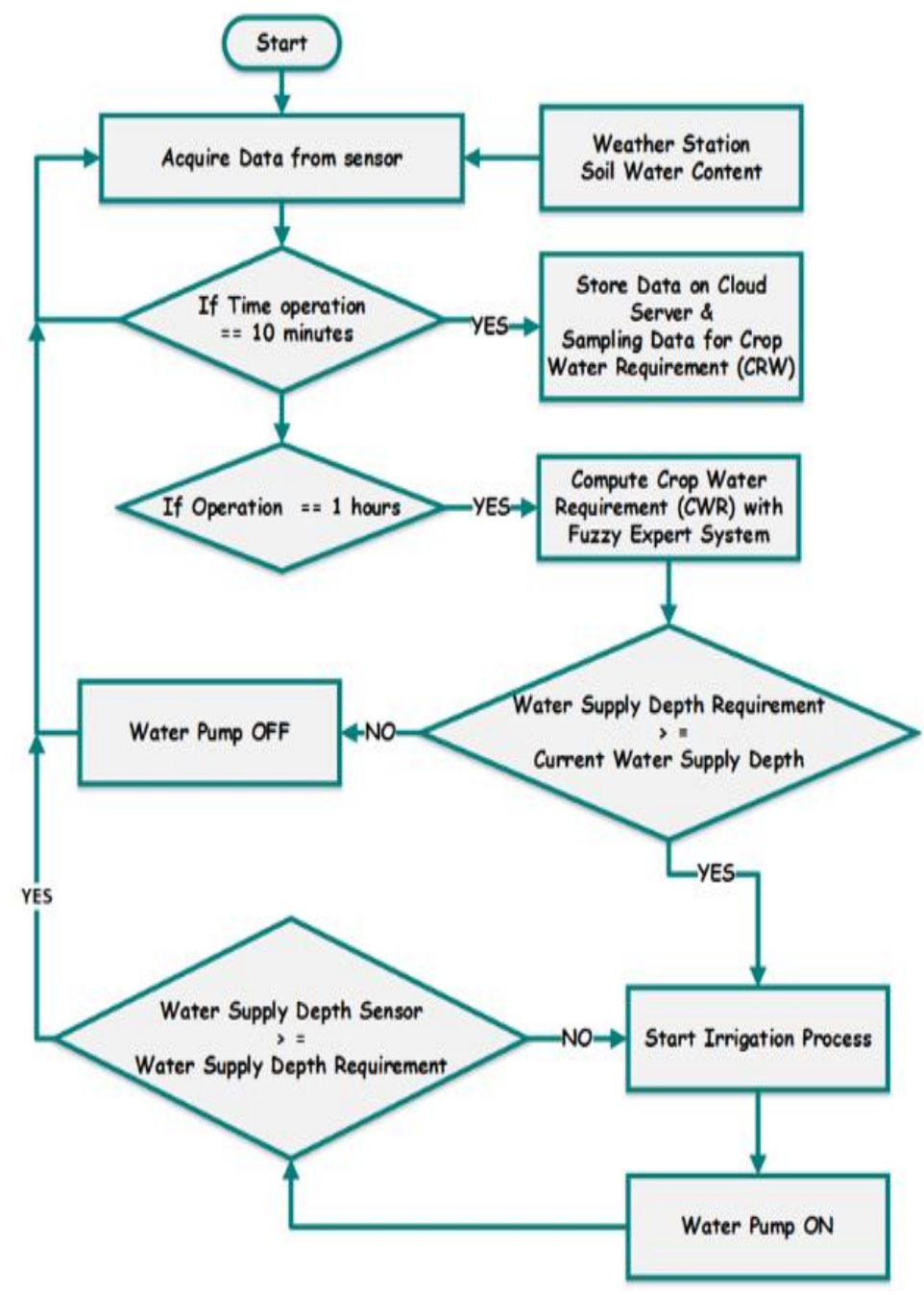

Figure 4. Flowchart of the irrigation process

\section{RESULTS AND DISCUSSION}

\subsection{IoT monitoring and the control system}

An experiment was carried out using the developed IoT system, in order to monitor and control the fibrous capillary irrigation system, as well as to test its performance on real time cultivation. The user interface was mainly composed of two parts, being a dashboard monitoring system and a database system. For the dashboard, the monitoring consisted of two sections, where one was the weather station, as shown in Figure 5 at the web page www.utmagritech.com/new/dashboard.php and the other is the fibrous capillary irrigation management system, as shown in Figure 6.

WEATHER STATION

Humidity: $99.90 \%$

Temperature: $24.40 \mathrm{C}$

Slr.Rad: $166.12 \mathrm{~W} / \mathrm{m}^{\wedge} 2$

UV Index: 0.94 Index

UV Value: 0.16 MED

WindDirection: 1 *

Rainfall: $5.25 \mathrm{~mm}$

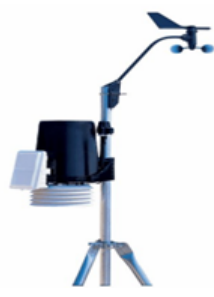
monitoring system
Figure 5. Dashboard for the weather station
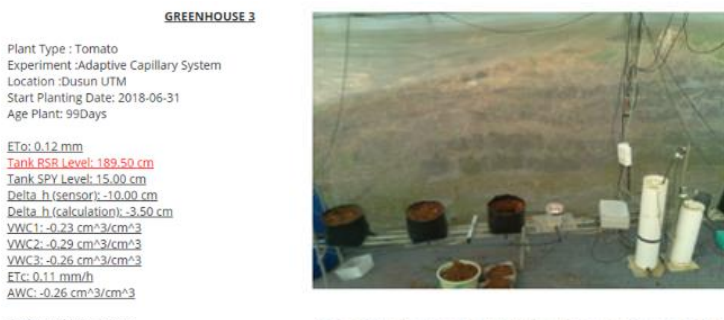

Tank Level Min: $2.0 \mathrm{~cm}$
Tank Level Max: $77.0 \mathrm{~cm}$
Figure 6. Dashboard for the monitoring fibrous capillary irrigation system 
The user interface updated the data every 10 minutes and the alert indicator showed if there were any warnings at the site. For example, the water reservoir tank set the alarm if the water level measured by the ultrasonic sensor was more than $500 \mathrm{~mm}$. Figure 7 shows an example of the e-mail that would be received from the IoT system, whenever the alarm was triggered. The data entry also had indicators, which were underlined at the reading sensor. If there was no data entry after 10 minutes at the database system, the dashboard showed the underlined data, in order to indicate that there was a system problem, such as no power supply, no router or a network failure.

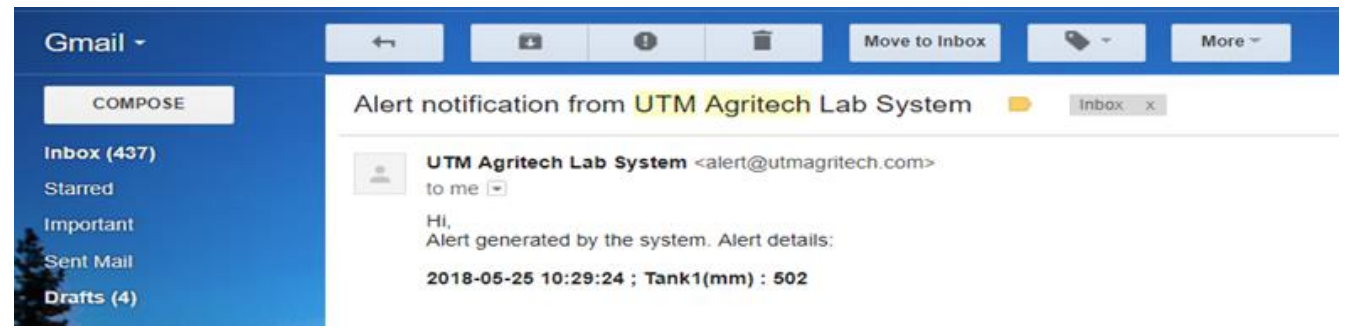

Figure 7. Alarm trigger system via e-mail

Figure 8 shows an example of an underlined indicator in the IoT module. The database data sensor reader collected the data every 10 minutes. Figures 9 and 10 shows the weather station and the irrigation database webpage. This database was divided into three sections, being a date time, a value and a unit sensor. From the user interface, the data can be downloaded, saved and printed.

\section{GREENHOUSE 1}

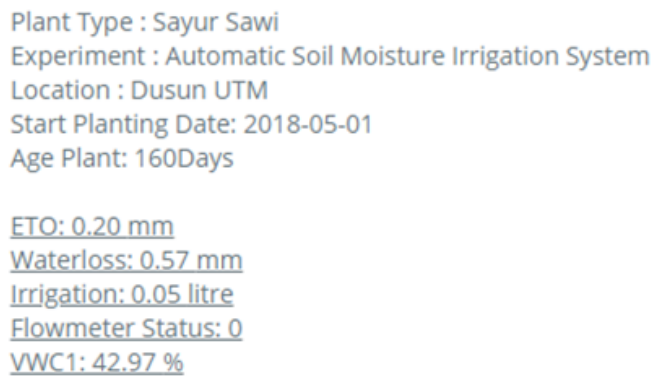

Figure 8. Alert data entry system if more than 10 minutes

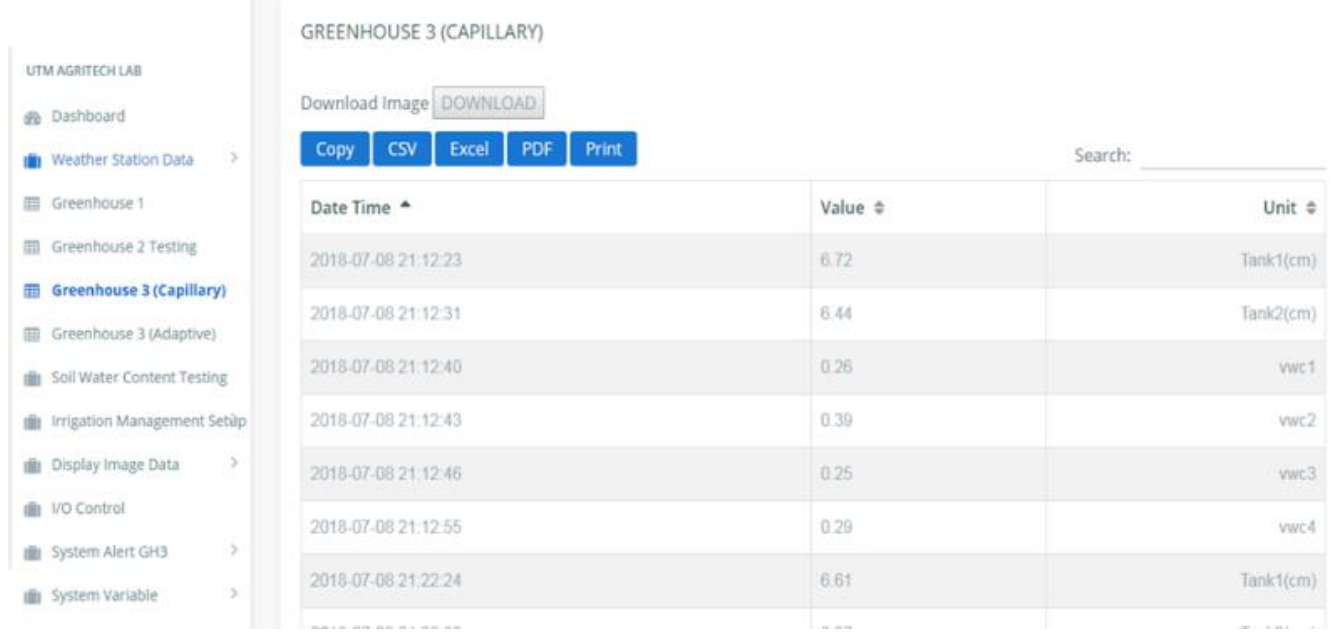

Figure 9. Weather station database system on the webpage 


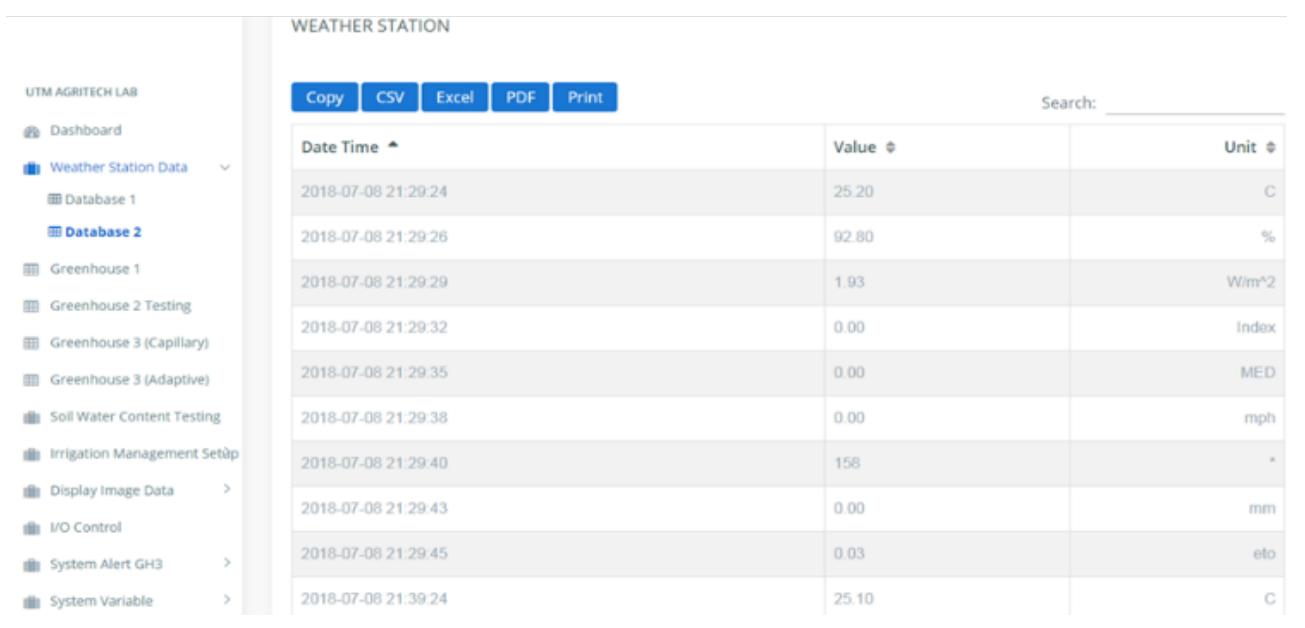

Figure 10. Fibrous capillary irrigation database system on the webpage

\subsection{Data monitoring system}

Figures 11 and 12 show the monitoring and the control results that were obtained in the period from 12 July 2018 to 24 July 2018. The irrigation parameters were successfully logged, and the volume was controlled based on the crop water demands. Figure 11 shows the evapotranspiration data that was logged hourly. The highest values of the ETo levels were shown on the dates of 12 July and 13 July and the lowest ETo level was on 14 July. Figure 12 shows the readings of the soil moisture content that were taken on three different Choy sum crops. Based upon the results, it can be seen that there were no deficit conditions of average soil moisture contents of between $0.2 \mathrm{~cm}^{3} / \mathrm{cm}^{3}$ and $0.3 \mathrm{~cm}^{3} / \mathrm{cm}^{3}$.

Figure 13 shows the water supply depth irrigation management levels that were based on the ETo levels and the soil moisture contents. The highest water level can be observed at $-8.3 \mathrm{~cm}$ and the lowest water level can be observed at a level of $-9.5 \mathrm{~cm}$. The overall performance of the fibrous capillary irrigation system was capable of meeting the demands, without any crop water stress, or without any over-irrigation.

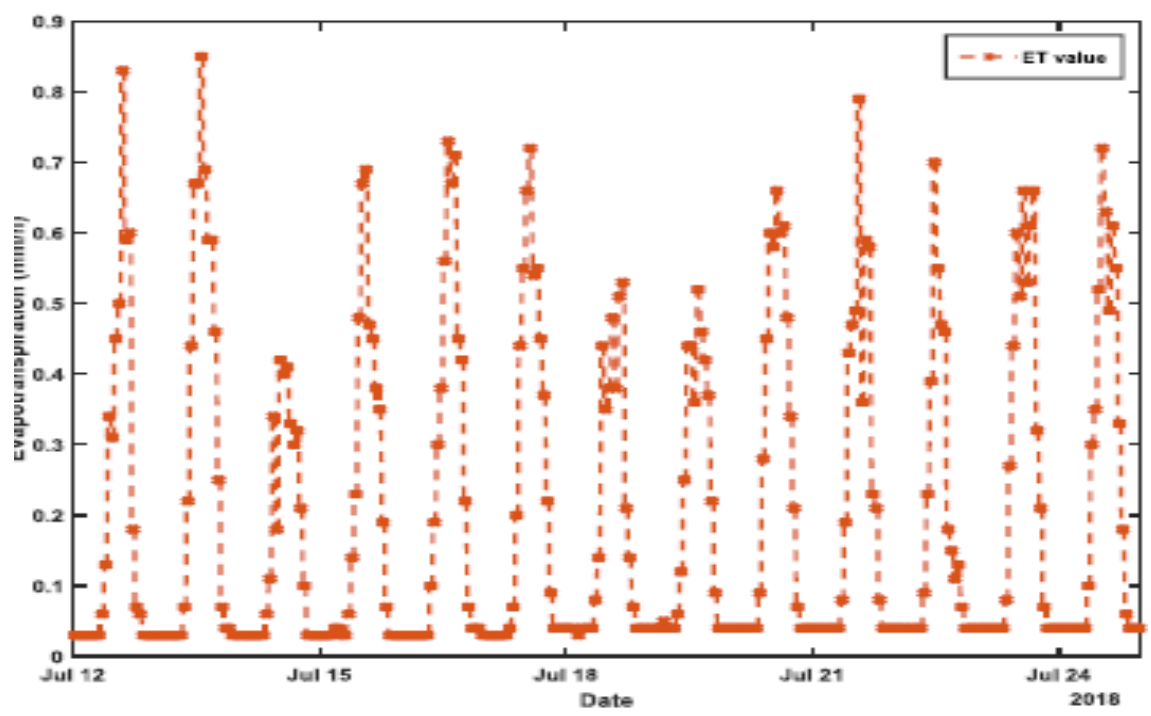

Figure 11. Evapotranspiration measurement sampling per hour 


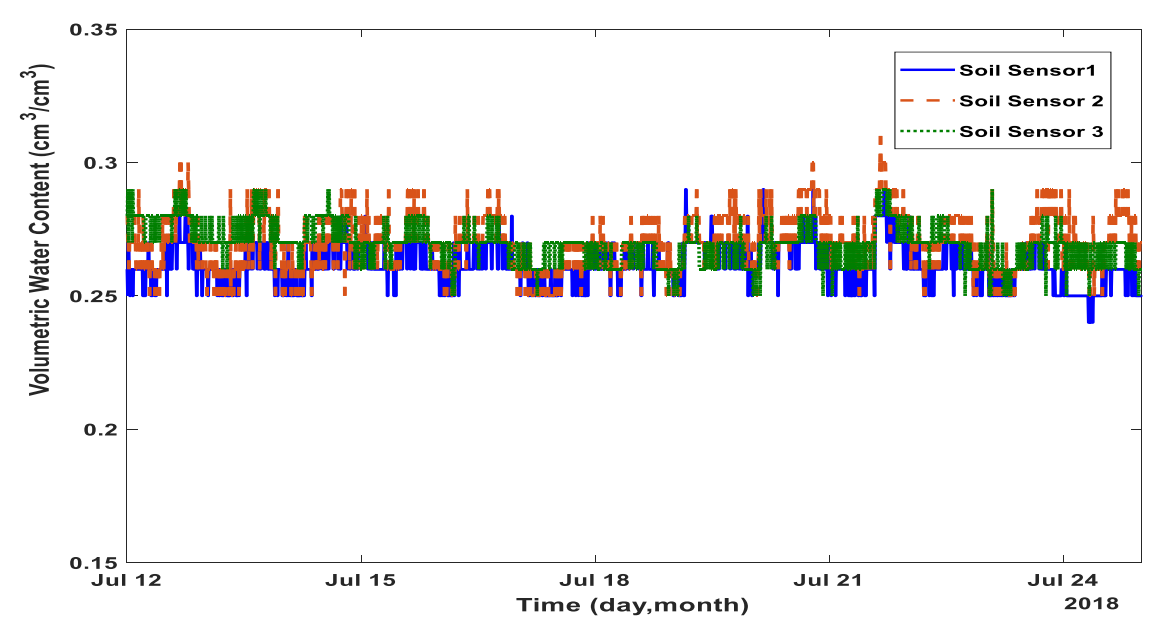

Figure 12. Soil moisture content measurements from each polybag

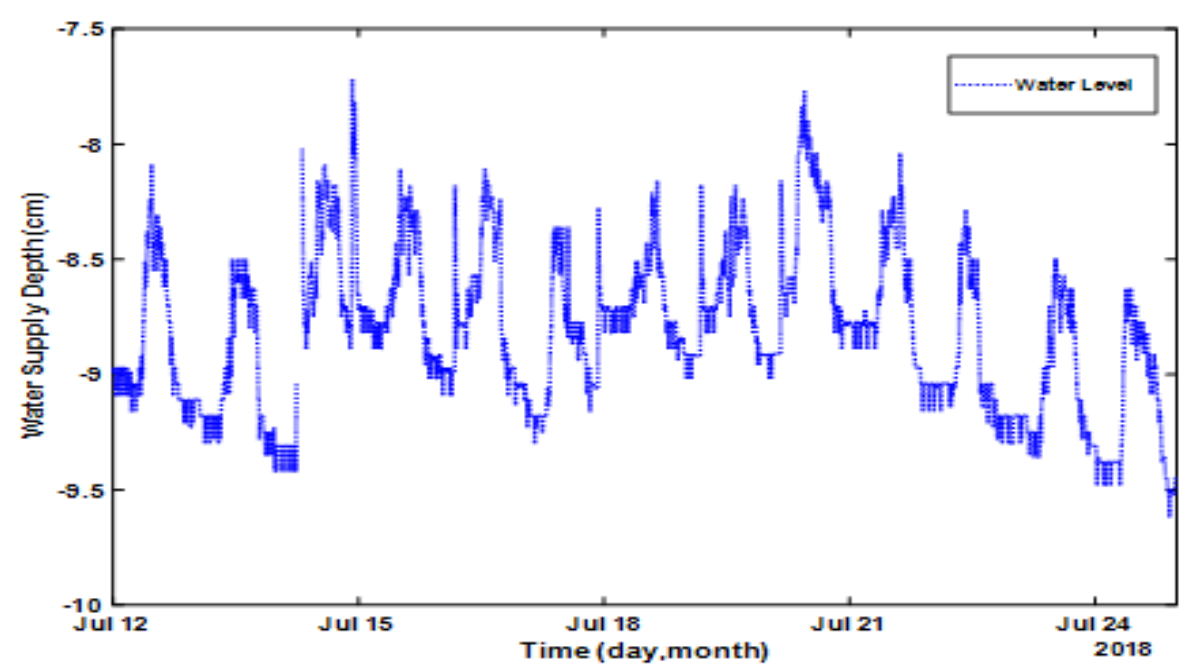

Figure 13. Water supply depth level measured from 12 July 2018 to 24 July 2018

\section{CONCLUSION}

In this study, the monitoring and the fibrous capillary irrigation control system has ben presented using the ETo with an IoT integration. The monitoring and control process were successfully developed at an affordable cost. The results have proven that an IoT system can be very useful for the near real time operation of a fibrous capillary irrigation system. The implementation of the management system in the field can be easily monitored. It can also reduce the cost of an expensive data logger system. An expansion for other irrigation systems can easily be integrated to the IoT system.

\section{ACKNOWLEDGEMENTS}

The authors are grateful to the University of Technology Malaysia for their partial financial support through their research Grant Funds, Vote No. Q. J130000.2523.19H29 and Q.JI30000.2523.17H45.

\section{REFERENCES}

[1] FAO, "Global agriculture towards 2050," High Lev. Expert Forum-How to Feed world 2050, pp. 1-4, Oct. 2009.

[2] I. Mohanraj, K. Ashokumar, and J. Naren, "Field Monitoring and Automation Using IOT in Agriculture Domain," Procedia Computer Science, vol. 93, no. September, pp. 931-939, 2016.

[3] A. Meola, "Why IoT, Big Data \& Smart Farming Are the Future of Agriculture-BI Intelligence Estimates," 2015. 
[4] Y. Mehta, "Agriculture Internet of Things (IoT) Technology|Applications," 2017.

[5] M. S. A. Mahmud, S. Buyamin, M. M. Mokji, and M. S. Z. Abidin, "Internet of Things based Smart Environmental Monitoring for Mushroom Cultivation," Indonesian Journal of Electrical Engineering and Computer Science, vol. 10, no. 3, pp. 847-852, 2018.

[6] A. J. Rau, J. Sankar, A. R. Mohan, D. Das Krishna and J. Mathew, "IoT based smart irrigation system and nutrient detection with disease analysis," 2017 IEEE Region 10 Symposium (TENSYMP), Cochin, 2017, pp. 1-4.

[7] O. Elijah, I. Orikumhi, T. A. Rahman, S. A. Babale and S. I. Orakwue, "Enabling smart agriculture in Nigeria: Application of IoT and data analytics," 2017 IEEE 3rd International Conference on Electro-Technology for National Development (NIGERCON), Owerri, 2017, pp. 762-766.

[8] Z. A. Shaikh, H. Yousuf, F. Nawaz, M. Kirmani, and S. Kiran, "Crop Irrigation Control using Wireless Sensor and Actuator Network ( WSAN )," 2010 International Conference on Information Emerging Technologies, 2010, pp. $1-5$.

[9] Y. Wang, J. Jin, and Q. Liu, "Research on Crop Dynamic Irrigation Lower Limit under Limited Water Supply 2-Method," 2016 Fifth International Conference on Agro-Geoinformatics, 2016, pp. 1-4.

[10] P. Xuanrong, Y. Tingdong, and W. Yuesheng, "Research and Design of Precision Irrigation System based on Artificial Neural Network,” 2018 Chinese Control Decis. Conf., pp. 3865-3870, 2018.

[11] M. S. Zainal Abidin, S. Shibusawa, M. Ohaba, Q. Li, and B. K. Marzuki, "Water Uptake Response of Plant in Subsurface Precision Irrigation System," Engineering in Agriculture, Environment and Food, vol. 6, no. 3, pp. 128-134, 2013.

[12] H. Liu, X. Wang, X. Zhang, L. Zhang, Y. Li, and G. Huang, "Evaluation on the Responses of Maize (Zea mays L.) Growth, Yield and Water Use Efficiency to Drip Irrigation Water under Mulch Condition in the Hetao Irrigation District of China," Agricultural Water Management, vol. 179, pp. 144-157, 2017.

[13] G. Chavarria and H. P. dos Santos, "Plant Water Relations: Absorption, Transport and Control Mechanisms," Advances in Selected Plant Physiology Aspects, pp. 105-132, 2012.

[14] J. Aguilar, D. Rogers, and I. Kisekka, "Irrigation Scheduling based on Soil Moisture Sensors and Evapotranspiration," Kansas Agricultural Experiment Station Research Reports, vol. 1, no. 5, pp. 1-6, 2015.

[15] M. K. I. Abd Rahman et al., "Enhanced Fertigation Control System Towards Higher Water Saving Irrigation," Indonesian Journal of Electrical Engineering and Computer Science, vol. 10, no. 3, pp. 859-866, 2018.

[16] P. Rajalakshmi and S. Devi Mahalakshmi, "IOT based Crop-Field Monitoring and Irrigation Automation," 10th International Conference on Intelligent Systems and Control. ISCO 2016, 2016. pp. 1-6.

[17] D. H. Rogers, "Soil, Water and Plant Relationships," K-State Res. Ext., vol. 1675, no. December, pp. 1-8, 2014.

[18] M. Adnan, M. Nazir, and M. A. Latif, "Estimating Evapotranspiration using Machine Learning Techniques," International Journal of Advanced Computer Science and Applications, vol. 8, no. 9, pp. 108-113, 2017.

[19] R. L. Snyder, S. Geng, M. Orang, and S. Sarreshteh, "Calculation and Simulation of Evapotranspiration of Applied Water," Journal of Integrative Agriculture, vol. 11, no. 3, pp. 489-501, 2012.

[20] C. Lozoya et al., "Model Predictive Control for Closed-Loop Irrigation," IFAC Proceeding Volumes, vol. 47, no. 3 , pp. 4429-4434, 2014.

[21] C. Lozoya, C. Mendoza, A. Aguilar, A. Román, and R. Castelló, "Sensor-Based Model Driven Control Strategy for Precision Irrigation," Journal of Sensors, vol. 2016, pp. 1-12, 2016.

[22] M. S. Zainal Abidin, S. Shibusawa, S. Buyamin, and Z. Mohamed, "Intelligent Control of Capillary Irrigation System for Water-Saving Cultivation,” 2015 10th Asian Control Conference, ASCC 2015, pp. 2-6, 2015.

[23] M. S. Zainal Abidin, S. Shibusawa, M. Ohaba, Q. Li, and M. Bin Khalid, "Capillary Flow Responses in a Soil-Plant System for Modified Subsurface Precision Irrigation,” Precision Agriculture, vol. 15, no. 1, pp. 17-30, 2014.

[24] H. T. T. Ngo and T. R. Cavagnaro, "Interactive Effects of Compost and Pre-Planting Soil Moisture on Plant Biomass, Nutrition and Formation of Mycorrhizas: A Context Dependent Response," Scientific Reports, vol. 8, no. 1, pp. 1-9, 2018.

[25] I. C. Dodd, J. Puértolas, K. Huber, J. G. Pérez-Pérez, H. R. Wright, and M. S. A. Blackwell, "The Importance of Soil Drying and Re-Wetting in Crop Phytohormonal and Nutritional Responses to Deficit Irrigation," Journal of Experimental Botany, vol. 66, no. 8, pp. 2239-2252, 2015.

\section{BIOGRAPHIES OF AUTHORS}

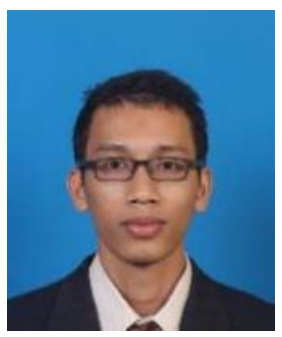

Muhammad Khairie Idham Abd Rahman recived his B. Eng in Electrical Engineering majored in Control and Mechatronics from Universiti Teknologi Malaysia (UTM) in 2016. Currently, he is pursuing his studies in Master of Philosophy of Electrical Engineering and his interest is in adaptive control for precision agricultural system for water saving. 


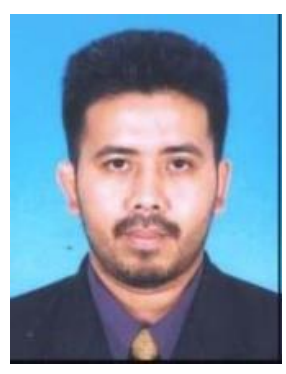

Mohamad Shukri Zainal Abidin received his B. Eng in Electrical Engineering from Universiti Teknologi Malaysia (UTM) in 1998, Msc in Electrical Engineering from Universiti Teknologi Malaysia (UTM) in 2001 and $\mathrm{PhD}$ in Agriculture Engineering from Tokyo University of Technology, Japan in 2014. Currently, he is a Senior Lecturer at Universiti Teknologi Malaysia (UTM) in Control and Mechatronics Department, Faculty of Electrical Engineering and his current research interest involve the adaptive control strategies in fibrous capillary irrigation system and agricultural robotics.

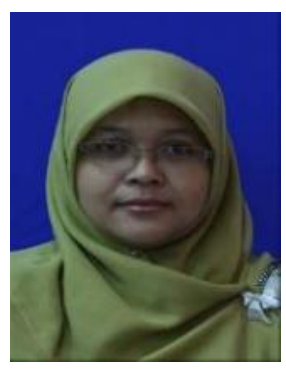

Salinda Buyamin received her B. Eng in Electrical Engineering from University of Toledo, USA in 1998, Msc in Automation and Control (Distinctio) from University of Newcastle, United Kingdom in 2003 and $\mathrm{PhD}$ in Control of Electrical Drives from University of Newcastle, United Kingdom in 2007. Currently, she is an Associate Professor at Universiti Teknologi Malaysia (UTM) in Control and Mechatronics Department, Faculty of Electrical Engineering and her current research interest involve the Modelling and Simulation of Dynamic Systems, Control and Development of Electric Drives System, System Identification and Estimation, Optimisation, Intelligent Control, Sensorless Control and Smart Agriculture System.

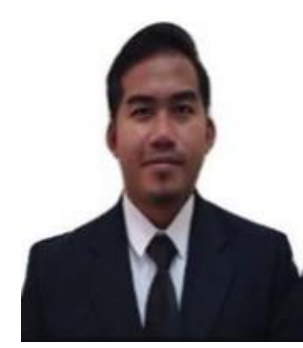

Mohd Saiful Azimi Mahmud received his B. Eng in Electrical Engineering, majored in Control and Mechatronics from Universiti Teknologi Malaysia (UTM) in 2015. Currently, he is pursuing his studies in Doctor of Philosophy of Electrical Engineering and his interest is in multiobjective optimization for agricultural mobile robot navigation system.

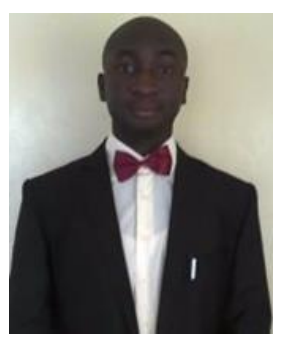

Abioye Abiodun Emmanuel received his B.Eng. degree in Electrical Engineering, and M.Eng in Electronics and Communication Engineering. Currently, he is pursuing his Doctor of Philosophy of Electrical Engineering at Universiti Teknologi Malaysia (UTM). His interest is on Internet of Things, Precision Agriculture, Artificial intelligence and Multivariable/Process Control system. 